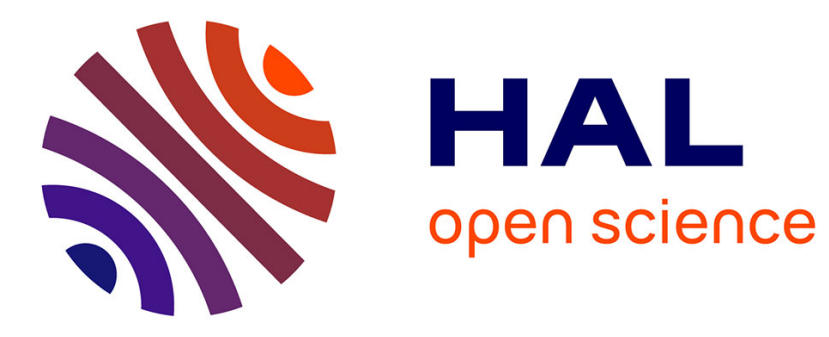

\title{
Circumventing Intrinsic Metal Reactivity: Radical Generation with Redox-Active Ligands
}

Jérémy Jacquet, Khaled Cheaib, Yufeng Ren, Hervé Vezin, Maylis Orio, Sébastien Blanchard, Louis Fensterbank, Marine Desage-El Murr

\section{- To cite this version:}

Jérémy Jacquet, Khaled Cheaib, Yufeng Ren, Hervé Vezin, Maylis Orio, et al.. Circumventing Intrinsic Metal Reactivity: Radical Generation with Redox-Active Ligands. Chemistry - A European Journal, 2017, 23 (60), pp.15030-15034. 10.1002/chem.201704049 . hal-01793183

\section{HAL Id: hal-01793183 \\ https://hal.science/hal-01793183}

Submitted on 16 May 2018

HAL is a multi-disciplinary open access archive for the deposit and dissemination of scientific research documents, whether they are published or not. The documents may come from teaching and research institutions in France or abroad, or from public or private research centers.
L'archive ouverte pluridisciplinaire HAL, est destinée au dépôt et à la diffusion de documents scientifiques de niveau recherche, publiés ou non, émanant des établissements d'enseignement et de recherche français ou étrangers, des laboratoires publics ou privés. 


\section{CHEMISTRY A European Journal}

\section{Accepted Article}

Title: Circumventing metallic intrinsic reactivity: radical generation with redox-active ligands

Authors: Jérémy Jacquet, Khaled Cheaib, Yufeng Ren, Hervé Vezin, Maylis Orio, Sébastien Blanchard, Louis Fensterbank, and Marine Desage-El Murr

This manuscript has been accepted after peer review and appears as an Accepted Article online prior to editing, proofing, and formal publication of the final Version of Record (VoR). This work is currently citable by using the Digital Object Identifier (DOI) given below. The VoR will be published online in Early View as soon as possible and may be different to this Accepted Article as a result of editing. Readers should obtain the VoR from the journal website shown below when it is published to ensure accuracy of information. The authors are responsible for the content of this Accepted Article.

To be cited as: Chem. Eur. J. 10.1002/chem.201704049

Link to VoR: http://dx.doi.org/10.1002/chem.201704049

Supported by

ACES 


\title{
Circumventing metallic intrinsic reactivity: radical generation with redox-active ligands
}

\author{
Jérémy Jacquet, ${ }^{[a]}$ Khaled Cheaib, ${ }^{[a]}$ Yufeng Ren, ${ }^{[a]}$ Hervé Vezin, ${ }^{[b]}$ Maylis Orio, ${ }^{[c]}$ Sébastien \\ Blanchard, ${ }^{[\mathrm{a}]}$ Louis Fensterbank ${ }^{[\mathrm{a}]}$ and Marine Desage-El Murr ${ }^{[\mathrm{a}, \mathrm{d}] *}$
}

\begin{abstract}
Nickel complexes have gained sustained attention as efficient catalysts in cross-coupling reactions and co-catalysts in dual systems due to their ability to react with radical species. Central to this reactivity is nickel's propensity to shuttle through several accessible redox states from $\mathrm{Ni}^{0}$ to $\mathrm{Ni}^{\mathrm{IV}}$. Here, we report the catalytic generation of trifluoromethyl radicals from a nickel complex bearing redox-active iminosemiquinone ligands. This unprecedented reactivity is enabled through ligand-based oxidation performing electron transfer to an electrophilic $\mathrm{CF}_{3}{ }^{+}$source while the nickel oxidation state is preserved. Additionally, extension of this reactivity to a copper complex bearing a single redox equivalent is reported, thus providing a unified reactivity scheme. These results open new pathways in radical chemistry with redox-active ligands.
\end{abstract}

The generation of radical species by organometallic catalytic manifolds is an area of intense investigation, largely sustained by the current interest in channeling their inherent high reactivity into productive catalytic systems. Among the leading methods for the generation of radicals are photoredox organometallic ${ }^{1}$ and organic ${ }^{2}$ manifolds. Both systems have garnered increasing attention due to the mild and easy-to-handle use of visible light as a cheap and waste-free activation source. Generation of radicals by these systems usually implies single-electron transfer (SET) between the photoinduced excited state of the catalyst and an organic substrate. ${ }^{3}$

Radical dual catalysis hinges on the productive merger of two sequential mono- and bis-electronic catalytic cycles. This field is at the forefront of task-performing systems for the synthetic integration of radicals generated by a primary cycle into a secondary catalytic cycle. ${ }^{4}$ Regarding the secondary catalytic cycle, a number of radical dual strategies involve nickel complexes, capitalizing on this metal's intrinsic ability to react with radicals and adopt several oxidation states (from $\mathrm{Ni}^{0}$ to

[a] J. Jacquet, Dr K. Cheaib, Y. Ren, Dr S. Blanchard, Prof. L. Fensterbank, Dr M. Desage-El Murr Sorbonne Universités, UPMC, Université Paris 06,UMR CNRS 8232, Institut Parisien de Chimie Moléculaire, France.

E-mail: marine.desage-el_murr@upmc.fr

[b] Dr H. Vezin

Laboratoire de Spectrochimie Infrarouge et Raman, Université des Sciences et Technologies de Lille, UMR CNRS 8516, 59655 Villeneuve d'Ascq Cedex, France.

[c] Dr M. Orio

Aix Marseille Université, CNRS, Centrale Marseille, iSm2 UMR 7313, 13397 Marseille cedex 20, France.

[d] Prof. M. Desage-El Murr

Institut de Chimie, Université de Strasbourg

1 rue Blaise Pascal 67000 Strasbourg, France.

E-mail : desageelmurr@unistra.fr

Supporting information for this article is given via a link at the end of the document.
$\left.\mathrm{Ni}^{\mathrm{iV}}\right){ }^{5}$ This behavior has been a stepping stone in the development of efficient catalytic methods ${ }^{6}$ and has provided a wealth of synthetic opportunities. ${ }^{7}$

Due to their unique electronic properties, redox-active ligands display an innate ability to promote ligand-centered redox events This striking feature can be used to alleviate metal-centered redox events, thus providing promising opportunities to develop alternative catalytic systems based on earth-abundant metals and/or provide new reactivity profiles altogether. ${ }^{8}$ Recent reports have established the possibility of fostering single-electron behavior with palladium complexes ${ }^{9}$ bearing redox-active amidophenolate ligands. ${ }^{8 \mathrm{~h}}$ In the case of electrocatalytic $\mathrm{C}-\mathrm{C}$ coupling reactions with $\mathrm{Ni}$-diimine complexes, spectroscopic evidences point towards a mechanism involving in the most reduced form a ligand-centered reduction. ${ }^{10}$ We have recently reported the use of a copper complex $\mathrm{Cu}\left(\mathrm{L}_{\mathrm{sQ}}\right)_{2}$ bearing noninnocent redox iminosemiquinone (SQ) ligands for the controlled generation of $\mathrm{CF}_{3}{ }^{\cdot}$ radicals and their application to the trifluoromethylation of heteroaromatics and silyl enol ethers, and the hydrotrifluoromethylation of alkynes. ${ }^{11}$ The redox iminosemiquinone ligand used in this system was shown to sustain the SET occurring between an electrophilic $\mathrm{CF}_{3}{ }^{+}$source and the complex, thereby being oxidized to the iminobenzoquinone $(B Q)$ form while the oxidation state of the metal center is preserved.

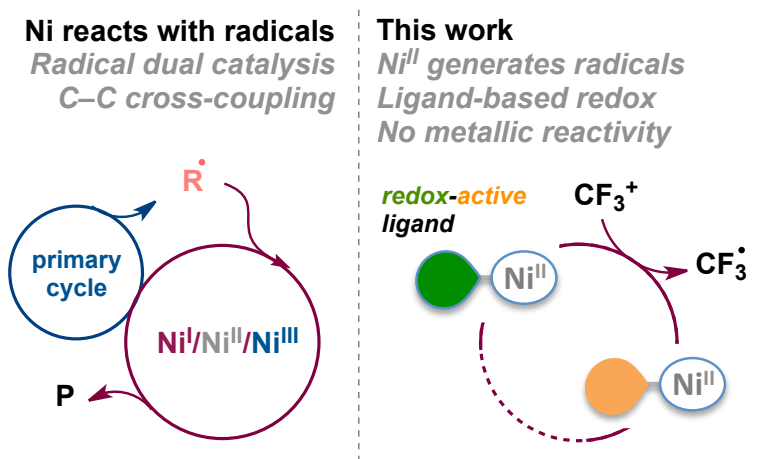

Figure 1. Classical nickel reactivity with radicals (left) and radical generation for nickel complexes enabled by redox-active ligands (right).

Here, we show that the use of such ligands can allow unprecedented nickel-catalyzed generation of trifluoromethyl radicals (Fig. 1). The redox transfer occurring between the electrophilic source and the nickel complex 1 is sustained by the redox-active ligand, thus overriding metal-based redox reactivity. We also report that the copper-catalyzed SET reactivity can be extended to another family of redox ligands bearing a single 
"redox equivalent", thus aiming towards the generalization of this approach.

In contrast with nickel's well-known affinity towards radicals, generation of radical species by nickel complexes is less documented but has been implicated in nickel-catalyzed crosscoupling reactions. ${ }^{6 c, f, g}$ Metal-centered redox transfers are involved in these examples but possible implication of a bipyridine ligand by delocalization of electronic density was reported in the nickel-based formation of carbon-centered radicals from an alkyl halide. ${ }^{12}$ Stepping away from alkyl radicals generation of $\mathrm{CF}_{3} \cdot$ radicals from nickel complexes has been reported by Vicic through homolytic splitting of $\mathrm{Ni}-\mathrm{CF}_{3}$ bond in BOXAM $^{13}$ and terpyridine ${ }^{14}$ nickel complexes. Interestingly, in the former case, study of the singly oxidized radical complex before dissociation showed a high extent of ligand-based oxidation at the BOXAM ligand. Although stoichiometric and occurring from preformed $\mathrm{Ni}-\mathrm{CF}_{3}$ complexes, these examples provide insights into the possible role of ligands in the generation of $\mathrm{CF}_{3} \cdot$ radical species from nickel complexes.

We were curious to explore the possibility of using redox ligands as a chemical handle towards the production of radical species by a nickel complex through ligand-based electronic transfer. The nickel complex used in this work is $\mathrm{Ni}\left(\mathrm{L}_{s \mathrm{Q}}\right)_{2}$ (complex 1 , see $\mathrm{SI}$ for preparation, Figure S1, tables $\mathrm{S} 1$ and $\mathrm{S} 2$ for X-Ray structure determination), a $\mathrm{Ni}^{\mathrm{il}}$ complex bearing two redox-active iminosemiquinone ligands. Its electronic structure was reported as a singlet diradical with a diamagnetic $d^{8}$ central metal ion and two strongly antiferromagnetically coupled $S Q$ radical ligands (see SI Figures S2-4 and Table S3 for theoretical data). ${ }^{15}$ No catalytic activity has been reported to date with this complex but related complexes with coordination spheres featuring iminosemiquinone-based motifs have been prepared, ${ }^{16}$ and more recently studied in heterobimetallic Au/Ni complexes. ${ }^{17}$ The initial assessment of our working hypothesis was carried out through TEMPO (2,2,6,6-tetramethylpiperidine- $N$-oxyl radical) trapping experiments (Table 1 ). Indeed, upon reacting complex 1 with an electrophilic $\mathrm{CF}_{3}{ }^{+}$source (2 or 3 ), the corresponding TEMPO- $\mathrm{CF}_{3}$ adduct was observed by ${ }^{19} \mathrm{~F}$ NMR spectroscopy, thus suggesting the formation of a $\mathrm{CF}_{3} \cdot$ radical in the reaction medium.

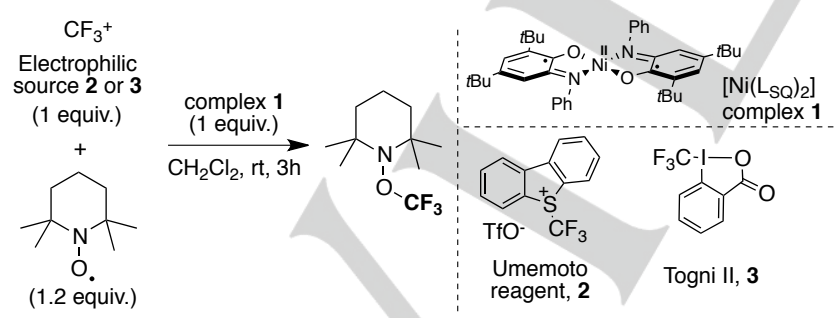

Table 1. TEMPO trapping experiments for the generation of radicals by complex 1.

\begin{tabular}{|c|c|c|c|c|}
\hline entry & complex & $\mathrm{CF}_{3}^{+}$source & Time & $\begin{array}{l}\text { TEMPO-CF } \\
\text { Yield }^{[a]}(\text { Conv. })^{]}\end{array}$ \\
\hline 1 & $\mathrm{Ni}\left(\mathrm{L}_{\mathrm{SQ}}\right)_{2} 1$ & 2 & $3 \mathrm{~h}$ & $66 \%(100 \%)$ \\
\hline 2 & $\mathrm{Ni}\left(\mathrm{L}_{\mathrm{sQ}}\right)_{2} 1$ & 3 & $3 h$ & $70 \%(100 \%)$ \\
\hline
\end{tabular}

\begin{tabular}{|c|c|c|c|c|}
\hline 3 & $\mathrm{Ni}\left(\mathrm{L}_{\mathrm{sQ}}\right)_{2} 1$ & 2 (2 equiv. $^{[\mathrm{b}]}$ & $24 \mathrm{~h}$ & $57 \%(75 \%)$ \\
\hline & $\mathrm{Ni}\left(\mathrm{L}_{\mathrm{SQ}}\right)_{2} 1$ & 3 (2 equiv. $^{[\mathrm{b}]}$ & $24 \mathrm{~h}$ & $46 \%(100 \%)$ \\
\hline
\end{tabular}

[a] Yields were determined by ${ }^{19} \mathrm{~F}$ NMR spectroscopy with fluorobenzene as an internal standard and calculated considering the trifluoromethylating agent as limiting reactant. [b] 2.4 equiv. of TEMPO were used.

UV-vis spectroscopy is an efficient tool for the monitoring of such electron transfer reactions as the original complex 1 displays an intense intervalence charge transfer band (IVCT) at $\lambda=880 \mathrm{~nm}$, due to the presence of two redox active iminosemiquinone ligands (Figure 2, blue trace). Similarly to earlier findings, ${ }^{11}$ no reaction was found to occur between 1 and TEMPO. Upon reaction of complex 1 with the $\mathrm{CF}_{3}{ }^{+}$source, one would expect the formation of $\mathrm{Ni}\left(\mathrm{L}_{S Q}\right)\left(\mathrm{L}_{B Q}\right)^{+}$complex 4 where one of the $S Q$ ligands has been oxidized upon ligand-based SET to a BQ ligand, as is observed in the case of the copper complex. ${ }^{11}$ However, the recorded UV-vis spectrum for the TEMPO-trapping experiments with complex 1 and $\mathrm{CF}_{3}{ }^{+}$source 2 (Figure 2 red trace) shows a decrease of only $50 \%$ of the IVCT band at $880 \mathrm{~nm}$, with an additional band growing around $480 \mathrm{~nm}$ similar to the electronic absorption signature of $\mathrm{Ni}\left(\mathrm{L}_{\mathrm{BQ}}\right)_{2}{ }^{2+} 5(\mathrm{SI}$ Figure S5). This spectrum displays the same profile as an equimolar mixture of complexes $\mathrm{Ni}\left(\mathrm{L}_{\mathrm{sQ}}\right)_{2} 1$ and fully oxidized $\mathrm{Ni}\left(L_{B Q}\right)_{2}{ }^{2+} 5$ (see $\mathrm{SI}$ for preparation and Figure S5 green trace). Monitoring the reaction by UV-vis at $25^{\circ} \mathrm{C}$ under argon atmosphere, shows a slow direct conversion of $\mathbf{1}$ to $\mathbf{5}$ which was illustrated by the presence of two isosbestic points at $360 \mathrm{~nm}$ and $590 \mathrm{~nm}$ (SI, Figures S6 and S7). These results are however not surprising and in agreement with the electrochemical studies reported by Wieghardt et al., ${ }^{15}$ which have shown a $2 \mathrm{e}$ reversible oxidation wave for the $\mathrm{Ni}\left(\mathrm{L}_{\mathrm{BQ}}\right)_{2}{ }^{2+} / \mathrm{Ni}\left(\mathrm{L}_{\mathrm{sQ}}\right)_{2}$ redox couple (see Figure S8 and table S4). The latter proceeds via an ECE (Electrochemical Chemical Event) mechanism with two successive SET.

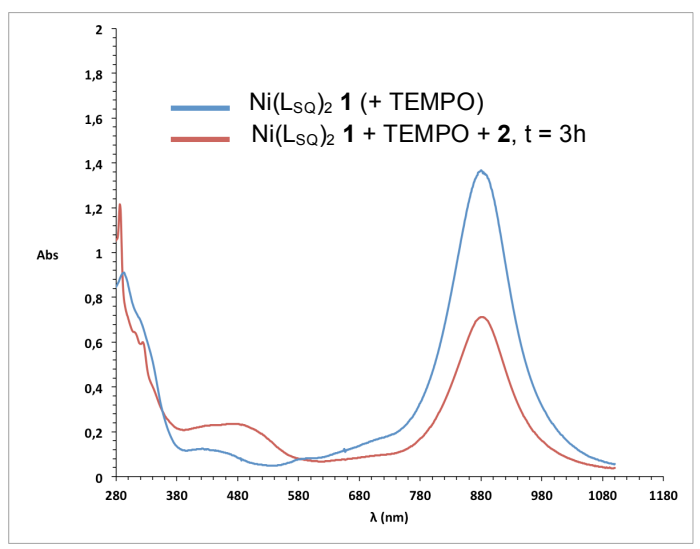

Figure 2. UV-vis studies for TEMPO-trapping experiments with complex 1 and $\mathrm{CF}_{3}{ }^{+}$source 2.

To get insight into the nature of the intermediate resulting from SET from complex 1 to the $\mathrm{CF}_{3}{ }^{+}$source we have undertaken DFT calculations. The structure of the putative species was subjected to geometry optimization (Figure S9) and its electronic structure was investigated. Our results indicate that the Singly 
Occupied Molecular Orbital (SOMO, Figure 3) is a delocalized $\pi$ orbital essentially distributed over the iminosemiquinone moieties of the system (Figure S10). The intermediate is best described as a ligand-based radical species with a doublet $S=1 / 2$ ground spin state, consistent with the formation of a $\mathrm{Ni}^{\prime \prime}\left(\mathrm{L}_{\mathrm{SQ}}\right)\left(\mathrm{L}_{\mathrm{BQ}}\right)^{+}$species (Table $\mathrm{S} 5$ ), which would support path $A$ (see SI scheme S1).

On a related note, the observation of a redox-induced coordinative rearrangement from an hemilabile bis-SQ-derived nickel complex upon single-electron oxidation has been reported, which supports this transient instability. ${ }^{16 \mathrm{c}}$ Nevertheless, the observation of the signature of $\mathrm{Ni}\left(\mathrm{L}_{\mathrm{BQ}}\right)_{2}{ }^{2+} \mathbf{5}$ in these UV-vis experiments clearly indicates that, in the SET transfer to $\mathrm{CF}_{3}{ }^{+}$, the resulting oxidation of $\mathbf{1}$ is ligand centered (see SI Figures S10-11 and Table S4 for theoretical data).

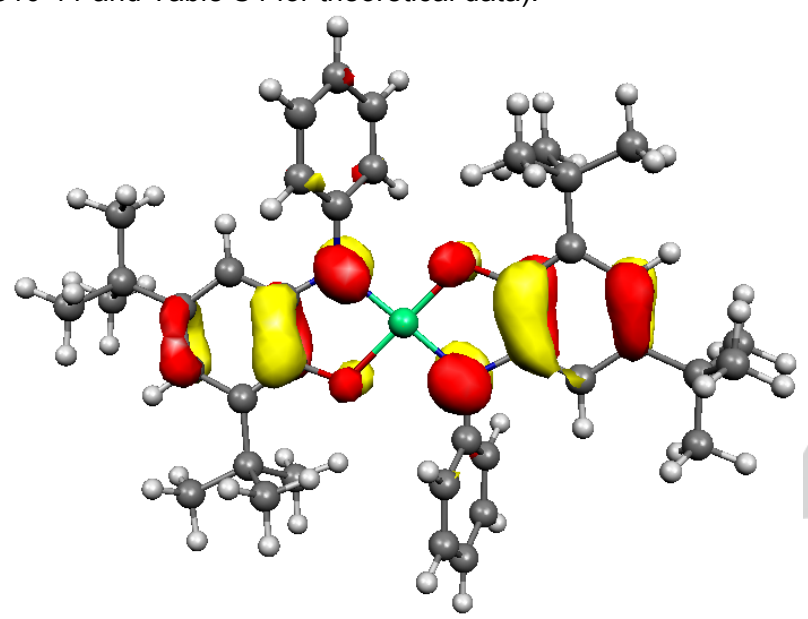

Figure 3. Localized $\mathrm{SOMO}$ for putative species $\left[\mathrm{Ni}\left(\mathrm{L}_{\mathrm{SQ}}\right)\left(\mathrm{L}_{\mathrm{BQ}}\right)\right]^{+} \mathbf{4}$ resulting from $\mathrm{SET}$ between complex $\mathrm{Ni}\left(\mathrm{L}_{\mathrm{sQ}}\right)_{2} 1$ with $\mathrm{CF}_{3}{ }^{+}$source.

Investigation of the synthetic applicability of these observations was implemented by reacting a catalytic amount of complex 1 with the electrophilic $\mathrm{CF}_{3}{ }^{+}$source and an organic substrate (Table 2). The isolation of trifluoromethylated product 6 from the reaction with 3-methylindole as the substrate shows that this reactivity can be useful synthetically.

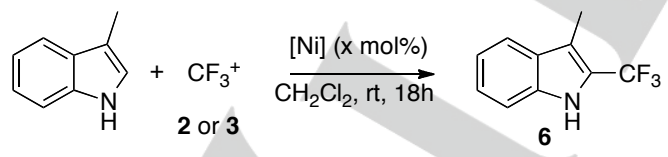

Table 2. Optimization studies for the transfer of generated $\mathrm{CF}_{3}$ radicals to 3-methylindole.

\begin{tabular}{|c|c|c|c|c|c|}
\hline entry & [Ni] source & $\begin{array}{l}\mathrm{x} \\
(\mathrm{mol} \%)\end{array}$ & $\begin{array}{l}\text { Substrate } \\
\text { equiv. }\end{array}$ & $\begin{array}{l}\mathrm{CF}_{3}^{+} \text {source } \\
\text { (equiv.) }\end{array}$ & Yield $^{[a]}$ \\
\hline 1 & $\mathrm{Ni}\left(\mathrm{L}_{\mathrm{SQ}}\right)_{2} 1$ & 20 & 4 & 2 (1 equiv.) & $12 \%$ \\
\hline 2 & $\mathrm{Ni}\left(\mathrm{L}_{\mathrm{sQ}}\right)_{2} 1$ & 20 & 4 & 3 (1 equiv.) & $69 \%$ \\
\hline 3 & $\mathrm{Ni}\left(\mathrm{L}_{\mathrm{SQ}}\right)_{2} 1$ & 20 & 1 & 3 (1.5 equiv.) & $\begin{array}{l}73 \% \\
78 \%{ }^{[b]}\end{array}$ \\
\hline
\end{tabular}

\begin{tabular}{lllccc}
4 & $\mathrm{Ni}\left(\mathrm{L}_{\mathrm{SQ}}\right)_{2} \mathbf{1}$ & 5 & 4 & $\mathbf{3}$ (1 equiv.) & $38 \%$ \\
5 & $\mathrm{Ni}(\mathrm{acac})_{2}$ & 20 & 1 & $\mathbf{3}(1.5$ equiv. $)$ & $20 \%$ \\
6 & $\mathrm{NiCl}_{2}(\mathrm{dme})$ & 20 & 1 & $\mathbf{3}(1.5$ equiv. $)$ & $2 \%$ \\
7 & none & - & 4 & $\mathbf{3}$ (1 equiv.) & traces \\
\hline
\end{tabular}

[a] Yields were determined by ${ }^{19} \mathrm{~F}$ NMR spectroscopy with fluorobenzene as an internal standard. [b] Isolated yield.

Optimal conditions were found to involve $20 \mathrm{~mol} \%$ of complex 1 and 1.5 equiv. of $\mathrm{CF}_{3}{ }^{+}$source 3 . Under these conditions, expected trifluoromethylated adduct 6 was obtained in $78 \%$ yield (entry 3). Interestingly, substituting isolated complex 1 with $\mathrm{Ni}(\mathrm{acac})_{2}$ or $\mathrm{NiCl}_{2}$ (dme) (entries 5 and 6) proved detrimental to the reaction, thus underscoring the central role of the redoxactive ligand. Also, control experiments confirm that the reaction does not work without catalyst. The reactivity observed towards the indole-based structure was successfully extended to the formation of $\alpha$-trifluoromethylated ketone 7 in $42 \%$ yield (from starting trimethylsilyl enol ether) (Scheme 1).

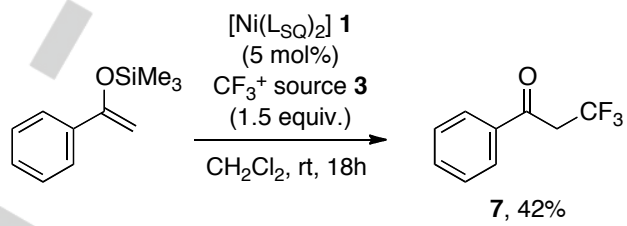

Scheme 1. Trifluoromethylation of a silyl enol ether by complex $1 .{ }^{19} \mathrm{~F}$ NMR yield was determined using fluorobenzene as internal standard.

Since the generation of radicals by SET between a redox-active complex and an oxidative source should inherently require only one electron form the ligand, it occurred to us that the use of two redox ligands was superfluous and that this reactivity should be feasible with complexes having only one "redox-equivalent" ligand. We selected the redox O,N,O ligand Cat-N-SQ $(\text { Cat=catechol, scheme } 2)^{18}$ and the reasons for this choice are three-fold (i) structural proximity with the original SQ ligand, (ii) distinct tridentate coordination sphere and (iii) only one oxidized state available. The nickel complex bearing one Cat-N-SQ ligand cannot be isolated as only the (Cat-N-SQ $)_{2} \mathrm{Ni}$ complex is recovered. ${ }^{18 a}$ However, [Cu" $(\mathrm{Cat}-\mathrm{N}-\mathrm{SQ})(\mathrm{Py})_{2}$ ] complex $\mathbf{8}$ is readily available ${ }^{18 b}$ and, considering our previous results on SET performed by copper complex $\mathrm{Cu}\left(\mathrm{LsQ}_{\mathrm{sQ}}\right)_{2} \mathbf{1},{ }^{11}$ its reactivity was investigated. Interestingly, complex 8 exhibits a similar behavior and TEMPO- $-\mathrm{CF}_{3}$ adduct was isolated in $57 \%$ yield (Scheme 2 ). Furthermore, complex 8 performs trifluoromethylation to provide compounds 6 and 7 in $68 \%$ and 59\% yield respectively, and hydrotrifluoromethylation of 1-dodecyne in $31 \%$ yield.

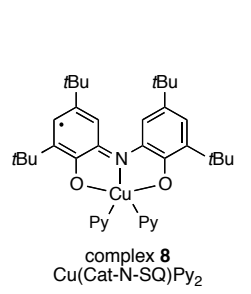

b)<smiles>CC1(C)CCCC(C)(C)N1OC(F)(F)F</smiles><smiles>Cc1c(C(F)(F)F)[nH]c2ccccc12</smiles><smiles>O=C(CC(F)(F)F)c1ccccc1</smiles>

complex 8
$\mathrm{Cu}($ Cat- $\mathrm{N}-\mathrm{SQ}) \mathrm{Py}_{2}$

4


Scheme 2. Generalization to a copper complex bearing a single redox equivalent. ${ }^{a} \mathrm{CF}_{3}{ }^{+}$source $2,{ }^{b} \mathrm{CF}_{3}{ }^{+}$source 3 . Reaction conditions for TEMPO$\mathrm{CF}_{3}$ and compounds $\mathbf{6}$ and $\mathbf{7}$ are identical to optimized conditions from Tables 1 and 2, and scheme 1 respectively. Catalyst loading: $20 \mathrm{~mol} \%$.

The UV-vis profiles of the TEMPO-trapping reactions (Figure 4, red and black spectra) were a close match to the UV-vis spectrum recorded upon independent oxidation of complex 8 with one equivalent of $\left.\left[\mathrm{Fc}_{\mathrm{C}}\right] \mathrm{PF}_{6}\right]$ (ferrocenium hexafluorophosphate, green spectrum) thus evidencing ligandbased SET from complex 8 for the formation of $\mathrm{CF}_{3} \cdot$ radicals. The EPR spectra of complex 8 before and after oxidation were recorded (SI, figure S12). As could be expected from the antiferromagnetic coupling between the ligand radical and the $\mathrm{Cu}^{\prime \prime}$ center ( $\mathrm{S}=0$ ground state), complex $\mathbf{8}$ is EPR silent (Figure S12 red trace). ${ }^{19}$ After reaction with the $\mathrm{CF}_{3}{ }^{+}$source in the presence of TEMPO, a strong axial signal with $a_{g / /}$ of 2.26 and $\mathrm{A}_{/ /}$of $152 \mathrm{G}$ (Figure $\mathrm{S} 12$ black trace), typical of a Cu-centered $\mathrm{S}=1 / 2$ spin (ie $\mathrm{Cu}^{\prime \prime}$ ) center is obtained, presumably resulting from the one electron oxidation of the ligand to the diamagnetic $L_{B Q}$ form. These results show that a "single redox-equivalent" ligand is enough to promote the reactivity.

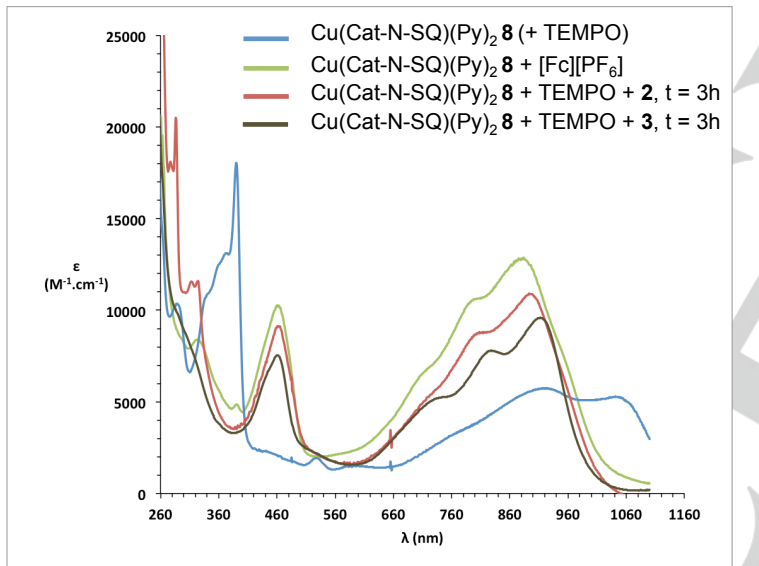

Figure 4. UV-vis spectra for TEMPO-trapping experiments of $\mathrm{CF}_{3}{ }^{+}$source with complex 8 .

In conclusion, we have demonstrated that the use of redoxactive ligands can outmanoeuvre nickel's intrinsic reactivity by promoting radical generation through single-electron transfer with an electrophilic $\mathrm{CF}_{3}{ }^{+}$source, thus enabling previously unreported catalytic reactivity. The extension to another family of redox ligands provides an outlook towards a unified reactivity scheme and the generalization of SET reactivity from redox ligands. Collectively, these results pave the way for future developments in the controlled generation of highly reactive species by redox organometallic systems.

\section{Experimental Section}

CCDC 1561909 (1) contain the supplementary crystallographic data for this paper. These data are provided free of charge by The Cambridge Crystallographic Data Centre.

\section{Acknowledgements}

The authors thank UPMC, CNRS, IR-RPE CNRS FR3443 RENARD network (CW X-band EPR with Dr. J.-L. Cantin, INSP UMR CNRS 7588, UPMC and X-band EPR in Lille). Sorbonne Universités is acknowledged for an Emergence Sorbonne Universités grant (MDEM and KC). Geoffrey Gontard and LiseMarie Chamoreau are acknowledged for XRD analysis and Omar Khaled for mass spectrometry. The authors gratefully acknowledge the support of this work by the COST Action 27 CM1305 ECOSTBio (Explicit Control Over Spin-States in Technology and Biochemistry).

Keywords: nickel $\cdot$ redox-active ligand $\cdot \mathrm{CF}_{3} \cdot$ radicals $\cdot$ single electron transfer

[1] a) M. D. Levin, S. Kim, F. D. Toste, ACS Cent. Sci. 2016, 2, 293-301; b) Y.-Y. Gui, L. Sun, Z.-P. Lu, D.-G. Yu, Org. Chem. 2016, 3, 522-526; c) J.-R. Chen, X.-Q. Hu, L.-Q. Lu, W.-J. Xiao, Chem. Soc. Rev. 2016, 45, 2044-2056; d) C. K. Prier, D. A. Rankic, D. W. C. MacMillan, Chem. Rev. 2013, 113, 5322-5363.

[2] a) J. Luo, J. Zhang, ACS Catal. 2016, 6, 873-877; b) S. Fukuzumi, K. Ohkubo, Org. Biomol. Chem. 2014, 12, 6059-6071; c) Romero, N. A Nicewicz, D. A. Chem. Rev. 2016, 116, 10075-10166.; d) C. Lévêque, L Chenneberg, V. Corcé, C. Ollivier, L. Fensterbank, Chem. Commun. 2016, 52, 9877-9880.

[3] S. P. Pitre, C. D. McTiernan, J. C. Scaiano, Acc. Chem. Res. 2016, 49, 1320-1330.

[4] a) M. N. Hopkinson, B. Sahoo, J.-L. Li, F. Glorius, Chem. - Eur. J. 2014, 20, 3874-3886; b) X. Lang, J. Zhao, X. Chen, Chem. Soc. Rev. 2016, 45, 3026-3038; c) J. J. Murphy, D. Bastida, S. Paria, M. Fagnoni, P. Melchiorre, Nature 2016, 532, 218-222.

[5] a) S. Z. Tasker, E. A. Standley, T. F. Jamison, Nature 2014, 509, 299309; b) N. M. Camasso, M. S. Sanford, Science 2015, 347, 1218-1220.

[6] a) X. Hu, Chem. Sci. 2011, 2, 1867-1886; b) J. Breitenfeld, J. Ruiz, M. D. Wodrich, X. Hu, J. Am. Chem. Soc. 2013, 135, 12004-12012; c) J. Breitenfeld, M. D. Wodrich, X. Hu, Organometallics 2014, 33, 57085715; d) T. J. Anderson, G. D. Jones, D. A. Vicic, J. Am. Chem. Soc. 2004, 126, 8100-8101; e) V. B. Phapale, E. Buñuel, M. García-Iglesias D. J. Cárdenas, Angew. Chem. 2007, 119, 8946-8951; Angew. Chem. Int. Ed. 2007, 46, 8790-8795; f) N. D. Schley, G. C. Fu, J. Am. Chem. Soc. 2014, 136, 16588-16593; g) V. B. Phapale, D. J. Cárdenas, Chem. Soc. Rev. 2009, 38, 1598-1607.

[7] a) J. C. Tellis, C. B. Kelly, D. N. Primer, M. Jouffroy, N. R. Patel, G. A. Molander, Acc. Chem. Res. 2016, 49, 1429-1439; b) O. Gutierrez, J. C. Tellis, D. N. Primer, G. A. Molander, M. C. Kozlowski, J. Am. Chem. Soc. 2015, 137, 4896-4899; c) C. L. Joe, A. G. Doyle, Angew. Chem. 2016, 128, 4108-4111; Angew. Chem. Int. Ed. 2016, 55, 4040-4043; d) J. C. Tellis, D. N. Primer, G. A. Molander, Science 2014, 345, 433-436; e) Z. Zuo, D. T. Ahneman, L. Chu, J. A. Terrett, A. G. Doyle, D. W. C. MacMillan, Science 2014, 345, 437-440; f) V. Corcé, L.-M. Chamoreau, E. Derat, J.-P. Goddard, C. Ollivier, L. Fensterbank, Angew. Chem. Int. Ed. 2015, 54, 11414-11418.

[8] a) H. Grützmacher, Angew. Chem. 2008, 120, 1838-1842; Angew. Chem. Int. Ed. 2008, 47, 1814-1818; b) P. J. Chirik, K. Wieghardt, Science 2010, 327, 794-795; c) V. K. K. Praneeth, M. R. Ringenberg, T. R. Ward, Angew. Chem. 2012, 124, 10374-10380; Angew. Chem. Int. 
Ed. 2012, 51, 10228-10234; d) J. I. van der Vlugt, Eur. J. Inorg. Chem. 2012, 363-375; e) S. Blanchard, E. Derat, M. Desage-El Murr, L. Fensterbank, M. Malacria, V. Mouriès-Mansuy, Eur. J. Inorg. Chem. 2012, 376-389; f) V. Lyaskovskyy, B. de Bruin, ACS Catal 2012, 2, 270 279; g) O. R. Luca, R. H. Crabtree, Chem. Soc. Rev. 2012, 42, $1440-$ 1459; h) D. L. J. Broere, R. Plessius, J. I. van der Vlugt, Chem. Soc. Rev. 2015, 44, 6886-6915; i) J. Jacquet, P. Chaumont, G. Gontard, M. Orio, H. Vezin, S. Blanchard, M. Desage-El Murr, L. Fensterbank, Angew. Chem. 2016, 128, 10870-10874; Angew. Chem. Int. Ed. 2016, 55, 10712-10716.

[9] a) D. L. J. Broere, B. de Bruin, J. N. H. Reek, M. Lutz, S. Dechert, J. I. van der Vlugt, J. Am. Chem. Soc. 2014, 136, 11574-11577; b) D. L. J. Broere, L. L. Metz, B. de Bruin, J. N. H. Reek, M. A. Siegler, J. I. van der Vlugt, Angew. Chem. 2015, 127, 1536-1540; Angew. Chem. Int. Ed. 2015, 54, 1516-1520; c) D. L. J. Broere, N. P. van Leest, B. de Bruin, M. A. Siegler, J. I. van der Vlugt, Inorg. Chem. 2016, 55, 8603-8611.

[10] A. Klein, A. Kaiser, B. Sarkar, M. Wanner, J. Fiedler, Eur. J. Inorg. Chem. 2007, 965-976.

[11] J. Jacquet, S. Blanchard, E. Derat, M. Desage-El Murr, L. Fensterbank, Chem. Sci. 2016, 7, 2030-2036.

[12] G. D. Jones, J. L. Martin, C. McFarland, O. R. Allen, R. E. Hall, A. D. Haley, R. J. Brandon, T. Konovalova, P. J. Desrochers, P. Pulay, D. A. Vicic, J. Am. Chem. Soc. 2006, 128, 13175-13183.

[13] A. Klein, D. A. Vicic, C. Biewer, I. Kieltsch, K. Stirnat, C. Hamacher, Organometallics 2012, 31, 5334-5341.

[14] C.-P. Zhang, H. Wang, A. Klein, C. Biewer, K. Stirnat, Y. Yamaguchi, L. Xu, V. Gomez-Benitez, D. A. Vicic, J. Am. Chem. Soc. 2013, 135, 8141-8144.

[15] P. Chaudhuri, C. N. Verani, E. Bill, E. Bothe, T. Weyhermüller, K. Wieghardt, J. Am. Chem. Soc. 2001, 123, 2213-2223.

[16] a) S. Kokatam, T. Weyhermüller, E. Bothe, P. Chaudhuri, K. Wieghardt, Inorg. Chem. 2005, 44, 3709-3717; b) E. Bill, E. Bothe, P. Chaudhuri, K Chlopek, D. Herebian, S. Kokatam, K. Ray, T. Weyhermüller, F. Neese, K. Wieghardt, Chem. - Eur. J. 2005, 11, 204-224; c) A. Paretzki, M. Bubrin, J. Fiedler, S. Záliš, W. Kaim, Chem. - Eur. J. 2014, 20, 54145422; d) A. V. Piskunov, I. V. Ershova, M. V. Gulenova, K. I. Pashanova, A. S. Bogomyakov, I. V. Smolyaninov, G. K. Fukin, V. K. Cherkasov, Russ. Chem. Bull. 2015, 64, 642-649; e) M. A. L. Sheepwash, A. J. Lough, L. Poggini, G. Poneti, M. T. Lemaire, Polyhedron 2016, 108, 2-7.

[17] D. L. J. Broere, D. K. Modder, E. Blokker, M. A. Siegler, J. I. van der Vlugt, Angew. Chem. 2016, 2452-2456; Angew. Chem. Int. Ed. 2016 , 55, 2406-2410.

[18] a) C. L. Simpson, S. R. Boone, C. G. Pierpont, Inorg. Chem. 1989, 28, 4379-4385; b) G. Speier, J. Csihony, A. M. Whalen, C. G. Pierpont, Inorg. Chem. 1996, 35, 3519-3524.

[19] As EPR is a very sensitive technique, traces of a $\mathrm{Cu}^{\text {"l }}$ species and of an organic radical have been detected, with an intensity more than 100 times lower than the final $\mathrm{Cu}^{\prime \prime}$ complex.

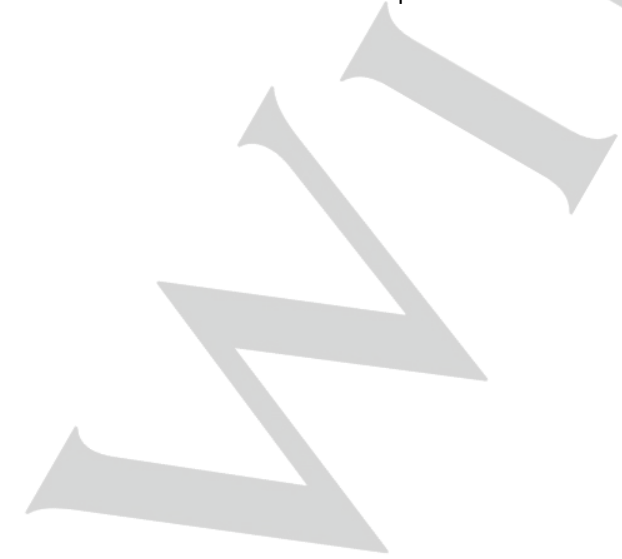




\section{Entry for the Table of Contents}

\section{COMMUNICATION}

Electro[Ni]c. Electronic transfer from a nickel complex bearing redox-active ligands to form radical species is studied. Combined UV-vis and DFT experiments suggest that the redoxactive ligands in the complex sustains this reactivity, while metal-based reactivity is outmaneuvered. This reactivity can be extended to a complex bearing a single "redoxequivalent".

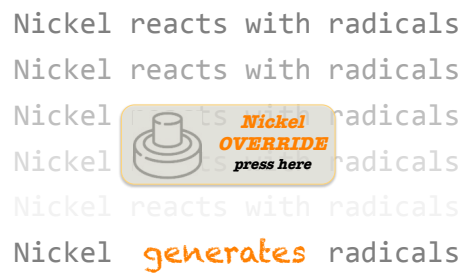

Nickel reacts with radicals

Nickel reacts with radicals

Nickel Mickel radicals

Nickel generates radicals

Jérémy Jacquet, Khaled Cheaib, Yufeng Ren, Hervé Vezin, Maylis Orio,

Sébastien Blanchard, Louis Fensterbank and Marine Desage-El Murr ${ }^{*}$

\section{Page No. - Page No.}

Circumventing metallic intrinsic reactivity: radical generation with redox-active ligands 